\title{
FTIR characterization and antioxidant activity of water soluble crude polysaccharides of Sri Lankan marine algae
}

\author{
I. P. Shanura Fernando ${ }^{1}$, K. K. Asanka Sanjeewa ${ }^{1}$, Kalpa W. Samarakoon ${ }^{2}$, Won Woo Lee ${ }^{1}$, \\ Hyun-Soo Kim ${ }^{1}$, Eun-A Kim ${ }^{1}$, U. K. D. S. S. Gunasekara ${ }^{2}$, D. T. U. Abeytunga ${ }^{3}$, Chandrika \\ Nanayakkara $^{3}$, E. D. de Silva ${ }^{3}$, Hyi-Seung Lee ${ }^{4}$ and You-Jin Jeon ${ }^{1, *}$ \\ ${ }^{1}$ Department of Marine Life Science, Jeju National University, Jeju 63243, Korea \\ ${ }^{2}$ Industrial Technology Institute (ITI), 363, Bauddhaloka Mawatha, Colombo 7, Sri Lanka \\ ${ }^{3}$ Colombo Science and Technology Cell, Faculty of Science, University of Colombo, Colombo 3, Sri Lanka \\ ${ }^{4}$ Marine Natural Products Laboratory, Korea Ocean Research and Development Institute, Ansan 15627, Korea
}

Polysaccharides of marine algae exhibit different structural characteristics and interesting biological functions. In this study, crude polysaccharides (CP) of eleven Sri Lankan marine algae obtained through hot water extraction and ethanol precipitation were investigated for DPPH, alkyl, and hydroxyl radical scavenging activities using electron spin resonance spectrometry and for intracellular reactive oxygen species scavenging activity in the Chang liver cell line. Characterization of CPs was done by Fourier transform infrared (FTIR) spectroscopy and by analysis of the monosaccharide composition. Time-dependent density functional theory quantum-chemical calculations at the RB3LYP/6-31G(d,p) level for constructed dimeric units of the corresponding polysaccharides were used to resolve the FTIR spectra. CPs from Chnoospora minima showed the highest DPPH and alkyl radical scavenging activities and higher intracellular reactive oxygen species scavenging effects for both AAPH and $\mathrm{H}_{2} \mathrm{O}_{2}$ induced ROS production in "Chang" cells. The major polysaccharide constituent in C. minima $\mathrm{CP}$ was identified as fucoidan and it displayed a higher sulfate content. The degree of sulfation of these polysaccharides suggests a positive correlation with the observed antioxidant properties.

Key Words: Chnoospora minima; electron spin resonance; FTIR analysis; polysaccharides; Sri Lankan

Abbreviations: AAPH, 2,2'-azobis(2-amidinopropane) dihydrochloride; AOAC, Association of Official Analytical Chemists; CP, crude polysaccharide; DCFH-DA, 2',7'-dichlorofluorescin diacetate; DFT, density functional theory; DMEM, Dulbecco's modified Eagle's medium; DPPH, 2,2-diphenyl-1-picrylhydrazy; FBS, fetal bovine serum; FTIR, Fourier transform infrared; IR, infrared; ROS, reactive oxygen species; SD, standard deviation; SLBS11, Chnoospora minima; SLGS1, Chaetomorpha antennina; SLGS1P, "P" after each sample name denote it's crude polysaccharide fraction; SLGS2, Halimeda discoidea; SLGS3, Halimeda gracilis; SLGS4, Caulerpa racemosa var. racemosa f. remota; SLRS10, Gracilaria edulis; SLRS5, Gracilaria corticata var. ramalinoides; SLRS6, Gracilaria foliifera; SLRS7, Ahnfeltiopsis pygmaea; SLRS8, Gracilaria corticata; SLRS9, Jania adhaerens; SPs, sulfated polysaccharides terms of the Creative Commons Attribution Non-Commercial License (http://creativecommons.org/licenses/by-nc/3.0/) which permits unrestricted non-commercial use, distribution, and reproduction in any medium, provided the original work is properly cited.
Received September 8, 2016, Accepted December 1, 2016

*Corresponding Author

E-mail: youjin2014@gmail.com

Tel: +82-64-754-3475, Fax: +82-64-756-3493 


\section{INTRODUCTION}

The ocean covers more than $70 \%$ of Earth's surface and is characterized by a wide diversity of marine organisms that offer a rich source of natural products (Wijesekara et al. 2011). Many wonders of this unique environment still remain a mystery. According to recent findings, marine organisms are rich in bioactive compounds that include polysaccharides, polyunsaturated fatty acids, polyphenolic compounds, antioxidants, peptides, essential vitamins and minerals (Heo et al. 2006, Kim et al. 2014, Lee et al. 2015). Sulfated polysaccharides (SPs) purified from algae and other organisms in particular, have been widely used in food, cosmetic, and pharmaceutical industries due to their broad spectrum of bioactivity and limited toxicity (Fleita et al. 2015). These macromolecules possess anticoagulant, antiviral, antioxidant, anticancer and immunomodulatory activities (Wijesekara et al. 2011, Nishiguchi et al. 2014, Kandasamy et al. 2015). They are mainly located in the cell walls of algae. Major SPs include fucoidans, laminaran and alginates from brown algae, carrageenans and agar from red algae and galactans, mannans and xylans from green algae (Percival 1979). The antioxidant activities of these bio-polymers have become an interesting research topic due to the role played by these molecules in defending the body against reactive oxygen species (ROS) (Vijayabaskar et al. 2012). Major ROS in biological systems include the superoxide radical, hydrogen peroxide, and the hydroxyl radical. They are generated during normal cellular metabolic processes and during pathogenic attacks (Yu 1994). Although enzyme mediated antioxidant cellular defense mechanisms exist, excessive production of ROS causes oxidative stress and cell damage.

Crude polysaccharides (CPs) and their enzyme hydrolysates from marine algae have shown interesting antioxidant properties. CPs composed of sulfated uronic acid residues from the brown alga Turbinaria ornata have demonstrated profound 2,2-diphenyl-1-picrylhydrazy (DPPH), nitric oxide and $\mathrm{ABTS}^{+}$radical scavenging activity and lipid peroxidation inhibition activities (Ananthi et al. 2010). Fucoidan, an SP extracted from Ecklonia cava has shown in vitro and in vivo anti-inflammatory activity in lipopolysaccharide induced RAW 264.7 macrophages and in zebrafish (Lee et al. 2013). SP from Sargassum swartzii reports being a good source of natural antioxidants with promising DPPH, ABTS', and $\mathrm{H}_{2} \mathrm{O}_{2}$ radical scavenging activities (Vijayabaskar et al. 2012). Unraveling the structural, compositional and sequential properties of these bioactive polysaccharides has become one of the major focuses of recent biochemical research (Pereira et al. 2013).

Sri Lankan marine algae have not been widely explored except in a few biochemical and ecological studies. Relevant literature includes the ecological and taxonomical study by Durairatnam (1961) and a study on the distribution and morphological features of Sri Lankan macroalgae (Coppejans et al. 2009). The earliest biochemical analysis focused on the identification of sterols from 18 Sri Lankan algae samples (Mahendran et al. 1980). Recently, attention has been payed to the biochemical properties and natural products of these algae. Lakmal et al. (2014) have reported the anticancer and antioxidant effects of several Sri Lankan marine algae including Chondrophycus ceylanicus, Gelidiella acerosa, Gracilaria corticata, Chaetomorpha crassa, Caulerpa racemose, and Sargassum cassifolium. Premakumara et al. (1996) have studied the post-coital contraceptive activity of crude extracts of $G$. corticata and G. acerosa and have isolated a non-steroidal contragestative agent, a sphingosine derivative from Gelidiella acerosa. There are no previous reports on the properties of polysaccharides from Sri Lankan algae. The aim of this study was to investigate the CPs of overlooked marine algae of the Sri Lankan coastal waters and explore their antioxidant properties.

\section{MATERIALS AND METHODS}

\section{Materials}

Polysaccharide standards (alginic acid from brown algae, A7003; fucoidan from Fucus vesiculosus, F5631; 1-carrageenan, C1138; agar, 56763) were purchased from Sigma-Aldrich (St. Louis, MO, USA). All organic solvents used during the sample preparation were of analytical grade. Chang liver cells were purchased from Korean Cell Line Bank (KCLB, Seoul, Korea). Dulbecco's modified Eagle's medium (DMEM) and fetal bovine serum (FBS) was purchased from Gibco Inc. (Grand Island, NY, USA). Potassium bromide (Fourier transform infrared [FTIR] grade) was purchased from Sigma-Aldrich.

\section{Collection of algal samples}

Chaetomorpha antennina (SLGS1), Halimeda discoidea (SLGS2), Halimeda gracilis (SLGS3), Gracilaria corticata var. ramalinoides (SLRS5), Gracilaria foliifera (SLRS6), Ahnfeltiopsis pygmaea (SLRS7), Gracilaria corticata (SLRS8), and Jania adhaerens (SLRS9) were col- 
lected from the cost of Galle, Sri Lanka $\left(6^{\circ} 4^{\prime} 54.19^{\prime \prime} \mathrm{N} /\right.$ $80^{\circ} 8^{\prime} 51.78^{\prime \prime}$ E). Caulerpa racemosa var. racemosa f. remota (SLGS4) was collected from the cost of Hikkaduwa, Sri Lanka ( $6^{\circ} 4^{\prime} 54.19^{\prime \prime} \mathrm{N} / 80^{\circ} 8^{\prime} 51.78^{\prime \prime}$ E) and Chnoospora minima (SLBS11), and Gracilaria edulis (SLRS10) were collected from the coast of Kalpitiya, Sri Lanka $\left(6^{\circ} 4^{\prime} 54.19^{\prime \prime} \mathrm{N}\right.$ / 80 ${ }^{\circ}{ }^{\prime} 51.78^{\prime \prime}$ E). Samples were identified by Dr. Chandrika Nanayakkara, a specialist in algal identification based on morphological and anatomical characters. Repositories were stored in the herbarium at the University of Colombo. Samples were washed thoroughly to remove any attached epiphytes and debris. Subsequently, samples were lyophilized, ground into a fine powder, and stored at $-20^{\circ} \mathrm{C}$ until further use.

\section{Extraction of crude polysaccharides (CPs)}

Algae powders (5.0 g each) were depigmented with acetone and extracted twice using distilled water at 90$95^{\circ} \mathrm{C}$ under continuous shaking for 3-4 h. Extracts were vacuum filtered and concentrated to one-fourth of the original volume. CPs were precipitated from extracts by adding three volumes of $95 \%$ ethanol bringing it up to the original volume. Mixtures were allowed to stand for $8 \mathrm{~h}$ at $4^{\circ} \mathrm{C}$. Precipitated $\mathrm{CPs}$ were separated by centrifugation $(12,000 \mathrm{rpm})$ at $4^{\circ} \mathrm{C}$. Hereafter the precipitate will be referred to as $\mathrm{CP}$ fraction.

\section{Chemical analysis}

The proximate composition of the 11 algal samples was analyzed according to the Association of Official Analytical Chemists (AOAC) 2005 methods. Accordingly, the protein content was determined with the standard Kjeldahl method, the lipid content with the Soxhlet method, and the ash content by dry ashing in a furnace at $550^{\circ} \mathrm{C}$ for $6 \mathrm{~h}$ (Horwitz and Latimer 2005). The total polysaccharide contents were analyzed using the phenol-sulfuric acid method as described by DuBois et al. (1956). The total polyphenolic content was analyzed according to the method described by Chandler and Dodds (1983) The protein content of the CPs was analyzed using the Thermo Scientific Pierce BCA protein assay kit (Thermo Scientific, Waltham, MA, USA). The sulfate content was measured with the $\mathrm{BaCl}_{2}$ gelation method (Dodgson and Price 1962).

\section{Evaluation of antioxidant activities}

The antioxidant activity of each $\mathrm{CP}$ fraction was analyzed as the measurement of DPPH, alkyl, and hydroxyl free radical scavenging activities. The analysis was done using an electron spin resonance spectrometer (JESFA200; Jeol, Tokyo, Japan) at $298 \mathrm{~K}$. The DPPH radicle scavenging activity was analysed according to the method described by Nanjo et al. method (Nanjo et al. 1996). The alkyl radical scavenging activity was analyzed according to the method described by Hiramoto et al.'s method (Hiramoto et al. 1993). The hydroxyl radical scavenging activity was evaluated according to the method described by Finkelstein et al. (1980).

\section{Cell culture}

"Chang" liver cells were maintained in DMEM supplemented with $1 \%$ antibiotic $\left(100 \mu \mathrm{gL} \mathrm{m}^{-1}\right.$ penicillin and 100 $\mu \mathrm{g} \mathrm{mL} \mathrm{m}^{-1}$ streptomycin) and $10 \% \mathrm{FBS}$. Cell cultures were maintained in incubators provided with a humidified atmosphere at $37^{\circ} \mathrm{C}$ with $5 \% \mathrm{CO}_{2}$. Cells were subcultured within each 2 days and the cells under exponential growth were seeded for experiments. Experiments were carried out using Chang cells seeded in 96 well culture plates following the same methods as described by Wijesinghe et al. (2011). Cytotoxicity of the CPs was evaluated as a measurement of cell viability using MTT colorimetric assay. Readings were obtained using a synergy HT multi-detection microplate reader (BioTek Inc., Winooski, VT, USA).

\section{Evaluation of intracellular ROS scavenging ac- tivities}

The $2^{\prime}, 7^{\prime}$-dichlorofluorescin diacetate (DCFH-DA) assay was adopted to evaluate the ROS scavenging ability of the CPs as described by Engelmann et al. (2005). Chang cells pre-seeded in 96-well plates at $1.0 \times 10^{5}{\text { cells } \mathrm{mL}^{-1}}^{-1}$ were treated with different sample concentrations. After $1 \mathrm{~h}$ of incubation, $\mathrm{H}_{2} \mathrm{O}_{2}(1 \mathrm{mM})$ or 2,2'-azobis (2-amidinopropane) dihydrochloride (AAPH; $10 \mathrm{mM}$ ) were added to each well except the control. After $1 \mathrm{~h}$ of incubation, DCFH-DA ( $25 \mu \mathrm{g} \mathrm{mL}^{-1}$ ) was added to each well following a 10 min incubation period. Fluorescence readings were obtained with a synergy HT multi-detection microplate reader at a $485 \mathrm{~nm}$ excitation and $530 \mathrm{~nm}$ emission wavelengths. 


\section{Characterization of CPs by Fourier transform infrared spectroscopy and neutral sugar analysis}

FTIR spectra of the CPs and standard fucoidan, agar, lambda-carrageenan, and alginic acid in $\mathrm{KBr}$ pellets were analyzed using an FTIR spectrometer (Nicolet 6700; Thermo Scientific). To analyze neutral sugars CPs were hydrolyzed using $4 \mathrm{M}$ of trifluoroacetic acid in sealed glass tubes. Analysis was carried out using the method described by Kang et al. (2015).

\section{Computational calculations}

Infrared (IR) vibrational wave numbers for designed dimeric units of polysaccharides were calculated using the Gaussian 09 package. Initial optimization of the molecular geometry was performed using the PM6 semi-empirical method. Geometry optimization and harmonic vibrational frequencies were calculated using time-dependent density functional theory (DFT) quantum-chemical calculations at the RB3LYP level using the 6-31G(d,p) basis set as described by Cardenas-Jiron et al. (2011). The calculated vibrational spectra were scaled with 0.9645 , 0.9799, 0.9819, 0.8625, 0.8719, and 0.9319 for alginic acid, fucoidan, sulfated galactan, mannan, agar, and lambda carrageenan, respectively.

\section{Statistical analysis}

All the data values are expressed as mean \pm SD based on at least three independent experiments. Statistical analysis for comparing the data was performed using IBM SPSS Statistics 20 software (IBM Corp., Armonk, NY, USA) using one-way ANOVA by Duncan's multiple range test. $\mathrm{p}$-values less than $0.05(\mathrm{p}<0.05)$ were considered as significant.

\section{RESULTS}

\section{Proximate composition}

As shown in Table 1, J. adhaerens showed the highest ash content followed by the two Halimeda species. The thallus of the aforementioned three algae species was highly calcified. The highest protein content was displayed by C. racemosa var. racemosa f. remota. The highest lipid content was shown by the two G. corticata species. The brown alga $C$. minima had the highest carbohydrate content followed by the red algae of the three Gracilaria species and $A$. pygmaea.

\section{Chemical composition}

The highest carbohydrate content was shown by SLRS10P with a percentage of $93.83 \pm 1.07 \%$ followed by SLGS1P with a percentage of $91.45 \pm 1.02 \%$ (Table 2 ). The protein content was higher in SLBS11P and SLRS8P. The highest phenolic and sulfate contents were observed in SLBS11P (Table 2).

Table 1. Proximate composition of the 11 Sri Lankan algae samples

\begin{tabular}{clccccc}
\hline Sample ID & \multicolumn{1}{c}{ Sample name } & $\begin{array}{c}\text { Moisture content } \\
(\%)\end{array}$ & $\begin{array}{c}\text { Ash content } \\
(\%)\end{array}$ & $\begin{array}{c}\text { Protein content } \\
(\%)\end{array}$ & $\begin{array}{c}\text { Lipid content } \\
(\%)\end{array}$ & $\begin{array}{c}\text { Carbohydrate } \\
\text { content }(\%)\end{array}$ \\
\hline Green algae & & & & & \\
SLGS1 & Chaetomorpha antennina & $2.11 \pm 0.08$ & $39.73 \pm 0.71$ & $13.56 \pm 0.09$ & $0.59 \pm 0.07$ & $42.21 \pm 0.32$ \\
SLGS2 & Halimeda discoidea & $0.82 \pm 0.08$ & $65.72 \pm 0.17$ & $17.42 \pm 0.47$ & $0.83 \pm 0.02$ & $13.61 \pm 0.21$ \\
SLGS3 & Halimeda gracilis & $0.41 \pm 0.03$ & $61.21 \pm 1.00$ & $20.08 \pm 0.33$ & $0.54 \pm 0.01$ & $15.11 \pm 0.35$ \\
SLGS4 & Caulerpa racemosa var. & $0.33 \pm 0.02$ & $60.67 \pm 0.72$ & $20.45 \pm 1.10$ & $0.64 \pm 0.07$ & $15.83 \pm 0.23$ \\
& racemosa f. remota & & & & \\
Red algae & & & & \\
SLRS5 & Gracilaria corticata var. & $1.53 \pm 0.06$ & $33.84 \pm 0.52$ & $16.74 \pm 0.06$ & $2.27 \pm 0.01$ & $43.31 \pm 0.46$ \\
& ramalinoides & & & & \\
SLRS6 & Gracilaria foliifera & $1.64 \pm 0.04$ & $39.42 \pm 0.38$ & $10.54 \pm 0.09$ & $0.94 \pm 0.06$ & $45.12 \pm 0.52$ \\
SLRS7 & Ahnfeltiopsis pygmaea & $0.56 \pm 0.04$ & $37.88 \pm 0.14$ & $16.25 \pm 0.14$ & $0.15 \pm 0.06$ & $43.61 \pm 0.35$ \\
SLRS8 & Gracilaria corticata & $0.83 \pm 0.06$ & $34.3 \pm 0.53$ & $10.26 \pm 0.27$ & $1.16 \pm 0.05$ & $50.21 \pm 0.09$ \\
SLRS9 & Jania adhaerens & $0.17 \pm 0.03$ & $73.45 \pm 0.70$ & $4.19 \pm 0.18$ & $0.01 \pm 0.01$ & $20.34 \pm 0.42$ \\
SLRS10 & Gracilaria edulis & $2.61 \pm 0.02$ & $38.17 \pm 0.49$ & $7.56 \pm 0.29$ & $0.45 \pm 0.07$ & $49.15 \pm 0.28$ \\
Brown algae & & & & & \\
SLBS11 & Chnoospora minima & $3.56 \pm 0.04$ & $14.54 \pm 0.02$ & $12.3 \pm 0.20$ & $0.25 \pm 0.05$ & $67.71 \pm 0.36$ \\
\hline
\end{tabular}

Values are presented as means \pm standard deviation $(n=3)$. 


\section{Radical scavenging activities of CPs}

The highest DPPH and alkyl radical scavenging activities were observed in SLBS11P with $\mathrm{IC}_{50}$ values of 89.51 \pm 17.00 and $106.80 \pm 0.66 \mu \mathrm{g} \mathrm{mL} \mathrm{m}^{-1}$, respectively (Table 3). The highest hydroxyl radical scavenging activity was observed in SLGS1P followed by SLBS11P. The antioxidant activity of standard ascorbic acid was measured using each respective radical scavenging assay. Accordingly, $\mathrm{IC}_{50}$ values were $23.22 \pm 0.52 \mu \mathrm{g} \mathrm{mL}^{-1}$ for the $\mathrm{DPPH}$ radical scavenging activity, $248.35 \pm 0.52 \mu \mathrm{g} \mathrm{mL}^{-1}$ for the hydroxyl radical scavenging activity and $35.62 \pm 0.41 \mu \mathrm{g} \mathrm{mL}^{-1}$ for the alkyl radical scavenging activity.

\section{Cytotoxicity and protective effects of CPs}

None of the CP fractions showed a considerable cyto- toxic effect on Chang cells at the concentrations tested (Fig. 1A). Cell viabilities were above $80 \%$ even in the presence of the highest concentration $\left(200 \mu \mathrm{g} \mathrm{mL} \mathrm{L}^{-1}\right)$. Results of the DCFH-DA assay indicate a reduction in the intracellular ROS levels of Chang cells, induced with $\mathrm{H}_{2} \mathrm{O}_{2}$ or AAPH in a dose-dependent manner compared to the respective positive control (Fig. 1B \& C). SLBS11P displayed the strongest scavenging effects. In addition to SLBS11P, a robust intracellular $\mathrm{H}_{2} \mathrm{O}_{2}$ scavenging activity was observed in SLGS1P $(\mathrm{p}<0.001)$.

\section{Structural analysis}

The assignment and characterization of IR vibrational spectra were done based on computational calculations performed on pre-designed monomeric and dimeric units of polysaccharides using the DFT method at the

Table 2. The chemical composition of the crude polysaccharide fraction

\begin{tabular}{|c|c|c|c|c|}
\hline \multirow{2}{*}{ Sample No. } & \multicolumn{2}{|c|}{ Total soluble carbohydrate content $(\%)$} & \multirow{2}{*}{$\begin{array}{l}\text { Total soluble } \\
\text { proteins (\%) }\end{array}$} & \multirow{2}{*}{$\begin{array}{c}\text { Total polypheno } \\
\text { content }(\%)\end{array}$} \\
\hline & Polysaccharide & Sulfate & & \\
\hline SLGS1P & $82.24 \pm 1.02$ & $9.21 \pm 0.30$ & $0.31 \pm 0.28$ & $2.60 \pm 0.16$ \\
\hline SLGS2P & $68.44 \pm 0.30$ & $5.20 \pm 0.17$ & $0.96 \pm 0.21$ & $4.04 \pm 0.00$ \\
\hline SLGS3P & $70.04 \pm 0.48$ & $5.20 \pm 0.08$ & $0.06 \pm 0.07$ & $3.93 \pm 0.47$ \\
\hline SLGS4P & $56.15 \pm 0.69$ & $10.51 \pm 0.37$ & $1.21 \pm 0.56$ & $4.38 \pm 0.79$ \\
\hline SLRS5P & $74.99 \pm 0.53$ & $1.65 \pm 0.29$ & $0.41 \pm 0.28$ & $4.27 \pm 0.00$ \\
\hline SLRS6P & $74.22 \pm 0.46$ & $4.08 \pm 0.33$ & $1.21 \pm 0.42$ & $4.60 \pm 0.15$ \\
\hline SLRS7P & $83.92 \pm 0.72$ & $4.55 \pm 0.25$ & $0.36 \pm 0.35$ & $4.04 \pm 0.00$ \\
\hline SLRS8P & $57.65 \pm 0.46$ & $9.84 \pm 0.75$ & $2.26 \pm 0.35$ & $4.71 \pm 0.00$ \\
\hline SLRS9P & $64.37 \pm 0.78$ & $2.82 \pm 0.54$ & $0.31 \pm 0.28$ & $4.16 \pm 0.16$ \\
\hline SLRS10P & $84.18 \pm 1.07$ & $9.65 \pm 0.16$ & $0.66 \pm 0.21$ & $3.93 \pm 0.05$ \\
\hline SLBS11P & $70.09 \pm 0.21$ & $11.80 \pm 0.79$ & $3.16 \pm 0.50$ & $4.83 \pm 0.16$ \\
\hline
\end{tabular}

Values are presented as means \pm standard deviation $(n=3)$.

Table 3. $I C_{50}$ values for the radical scavenging activities of crude polysaccharide fractions

\begin{tabular}{lccc}
\hline & \multicolumn{3}{c}{ IC $_{50}$ values for radical scavenging activity $\left(\boldsymbol{\mu g} \mathbf{~ m L}^{-1}\right)$} \\
\cline { 2 - 4 } Sample No. & DPPH & Alkyl & Hydroxyl \\
\cline { 2 - 4 } SLGS1P & $>2,000$ & $278.18 \pm 0.75$ & $102.68 \pm 16.00$ \\
SLGS2P & $>2,000$ & $110.06 \pm 2.98$ & $1,008.65 \pm 8.19$ \\
SLGS3P & $>2,000$ & $116.60 \pm 2.59$ & $1,006.90 \pm 6.40$ \\
SLGS4P & $>2,000$ & $359.48 \pm 20.54$ & $200.08 \pm 8.17$ \\
SLRS5P & $>2,000$ & $367.43 \pm 1.74$ & $654.13 \pm 9.14$ \\
SLRS6P & $1,654 \pm 37.46$ & $382.55 \pm 1.23$ & $582.47 \pm 9.29$ \\
SLRS7P & $>2,000$ & $377.24 \pm 6.10$ & $768.92 \pm 8.10$ \\
SLRS8P & $603.38 \pm 40.3$ & $332.33 \pm 15.29$ & $287.63 \pm 13.68$ \\
SLRS9P & $>2,000$ & $114.59 \pm 5.01$ & $281.70 \pm 4.96$ \\
SLRS10P & $>2,000$ & $113.09 \pm 7.13$ & $602.95 \pm 12.26$ \\
SLBS11P & $89.51 \pm 17.00$ & $106.80 \pm 0.66$ & $193.57 \pm 3.38$ \\
Ascorbic acid & $23.22 \pm 0.52$ & $35.62 \pm 0.41$ & $248.35 \pm 0.52$ \\
\hline
\end{tabular}

Values are presented as means \pm standard deviation $(n=3)$. 

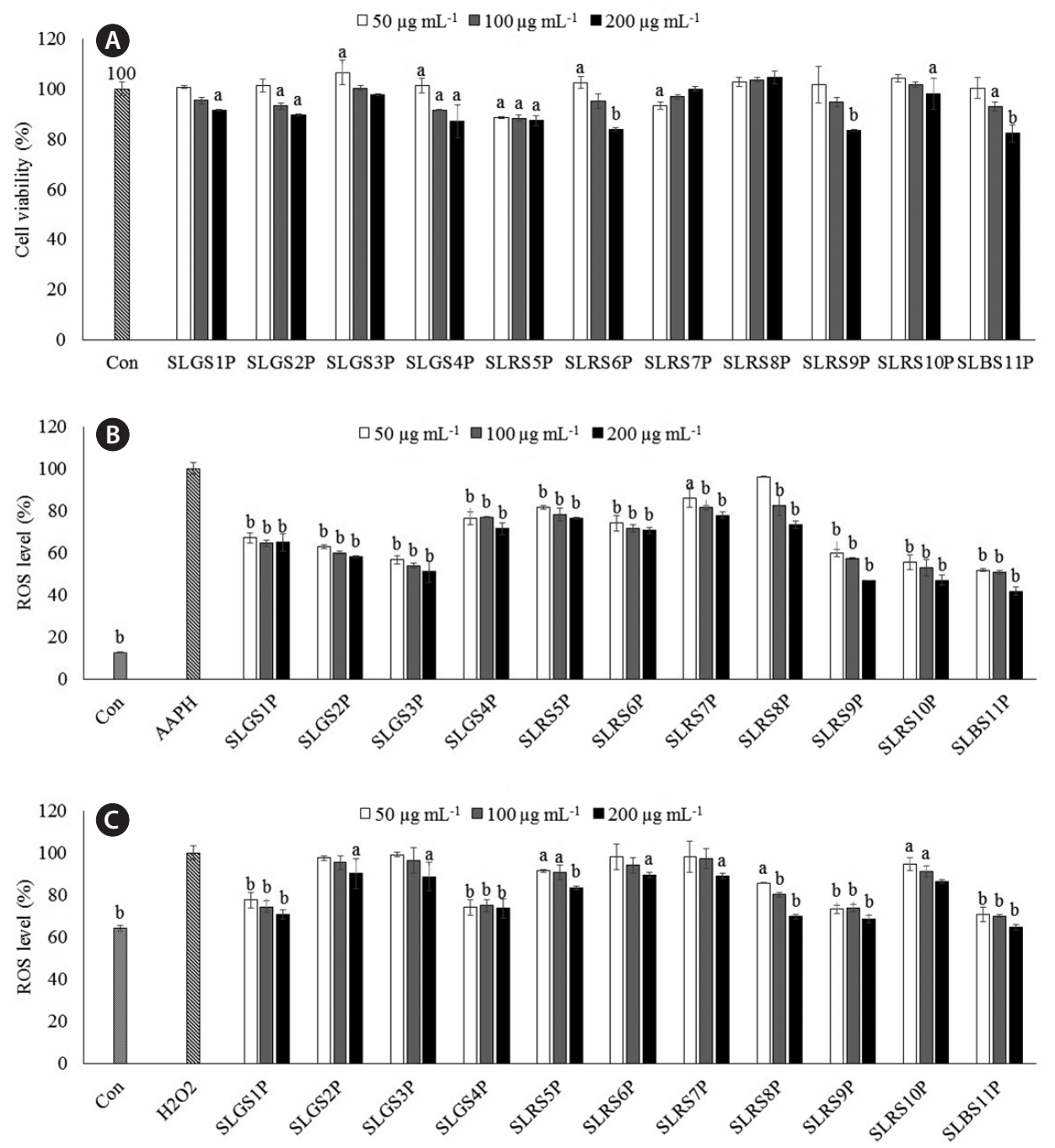

Fig. 1. Evaluation of sample toxicity and intracellular reactive oxygen species (ROS) scavenging activities of the samples against $\mathrm{H}_{2} \mathrm{O}_{2}$ and 2,2'-azobis(2-amidinopropane) dihydrochloride (AAPH) induced oxidative stress in "Chang" cells. (A) Sample toxicity. (B) AAPH induced intracellular ROS scavenging activity. (C) $\mathrm{H}_{2} \mathrm{O}_{2}$ induced intracellular ROS scavenging activity. Results represent the percentage (\%) of cell viability and intracellular ROS levels. Values were obtained from three independent experiments and represented as means \pm standard deviation. ${ }^{\mathrm{a}} \mathrm{p}<0.05$ and ${ }^{\mathrm{b}} \mathrm{p}<0.001$ were considered as significant compared to the control (sample toxicity) and positive control (ROS scavenging).

RB3LYP/6-31G(d,p) level and based on relevant literature (Tul'chinsky et al. 1976, Christiaen and Bodard 1983, Mathlouthi and Koenig 1987, Mollet et al. 1998, Roberts and Quemener 1999, Marais and Joseleau 2001, Pereira et al. 2003, 2013, Chandía et al. 2004, Praiboon et al. 2006, Leal et al. 2008, Alves et al. 2010, Ji et al. 2013, Xia et al. 2014). Fig. 2 shows the structures of the constructed dimeric units and their corresponding energy values.

The calculated FTIR spectra are shown in Fig. 3. The IR spectra within the $500 \mathrm{~cm}^{-1}$ to $2,000 \mathrm{~cm}^{-1}$ wavenumber region (fingerprint region for polysaccharides) were used for data analysis. Table 4 summarizes some of the major IR vibrational modes of polysaccharides (Mathlouthi and
Koenig 1987, Mollet et al. 1998, Alves et al. 2010, Pereira et al. 2013). All FTIR spectra identify a basic polysaccharide backbone with an intense peak centering $1,035 \mathrm{~cm}^{-1}$ representing the stretching vibrations of the glycoside bridge $(\mathrm{C}-\mathrm{O}-\mathrm{C})$ (Pereira et al. 2013). This intense peak is broadened $\left(1,010-1,090 \mathrm{~cm}^{-1}\right)$ due to the overlap with of other peaks (Pereira et al. 2003, Xia et al. 2014).

Considering the polysaccharides found in brown algae, except for the characteristic IR peaks shared by polysaccharides, the band at $1,135 \mathrm{~cm}^{-1}$ (Fig. 3A) in SLBS11P and fucoidan standard indicates stretching vibrations of the glycosidic $\mathrm{C}-\mathrm{O}$ group of fucoidan. The broadened peak between $1,120-1,270 \mathrm{~cm}^{-1}$ indicate sulfate groups $(\mathrm{S}=\mathrm{O}$ 
A

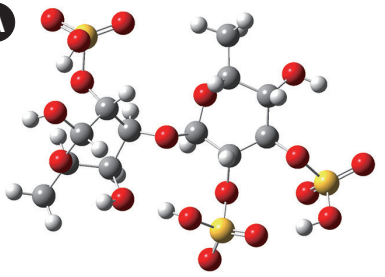

Fucoidan

$\mathrm{G}_{\mathrm{f}}{ }^{\mathrm{g}}=-\mathbf{7 , 9 2 5 , 2 3 9 . 7 4} \mathrm{kJ} \mathrm{mol}^{-1}$

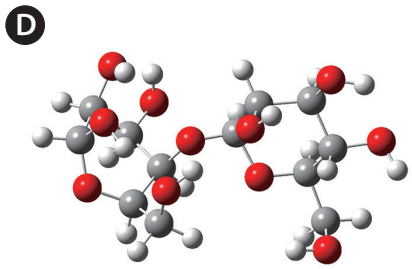

Mannan
$\mathrm{G}_{\mathrm{f}}{ }^{\mathrm{g}}=\mathbf{- 3 , 4 0 6 , 9 3 2 . 0 7} \mathrm{kJ} \mathrm{mol}^{-1}$
B

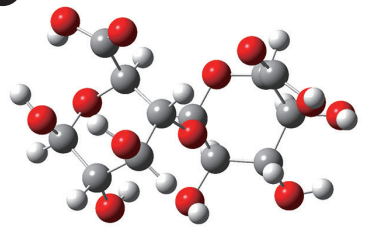

Alginic acid $\mathrm{G}_{\mathbf{f}}{ }^{\mathrm{g}}=-\mathbf{3}, 795,743.52 \mathrm{~kJ} \mathrm{~mol}^{-1}$

E

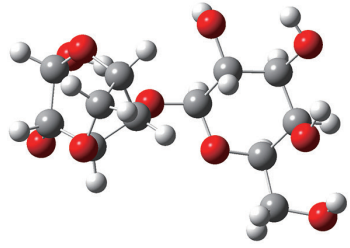

Agar
$\mathrm{G}_{\mathrm{f}}{ }^{\mathrm{g}}=\mathbf{- 3}, \mathbf{2 0 6 , 2 5 8 . 0 4} \mathrm{kJ} \mathrm{mol}^{-1}$ c

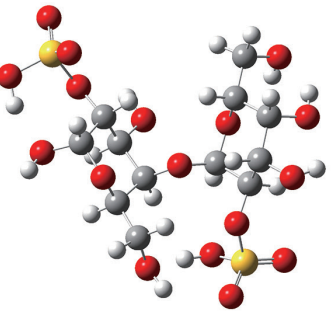

Sulfated galactan $\mathrm{G}_{\mathrm{f}}{ }^{\mathrm{e}}=-\mathbf{6}, 682,436.09 \mathrm{~kJ} \mathrm{~mol}^{-1}$

$\boldsymbol{F}$

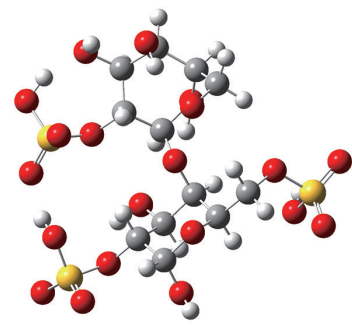

Lambda carrageenan $\mathrm{G}_{\mathrm{f}}{ }^{0}=\mathbf{- 8 , 3 2 0 , 1 8 4 . 7 2} \mathrm{kJ} \mathrm{mol}^{-1}$

Fig. 2. Optimized molecular geometries of the modeled dimeric units of polysaccharide residues. (A) Fucoidan. (B) Alginic acid. (C) Sulfated galactan. (D) Mannan. (E) Agar. (F) Lambda carrageenan. Computational calculations were performed using density functional theory method at RB3LYP/6-31G(d,p) level. $\mathrm{G}_{f}^{\sigma}$ represents the "Sum of electronic and thermal Free energies" (Gibbs free energy) of the molecule in kJ mol ${ }^{-1}$. Color code for spheres: yellow, sulfur; red, oxygen; blue, nitrogen; grey, carbon; white, hydrogen.

A

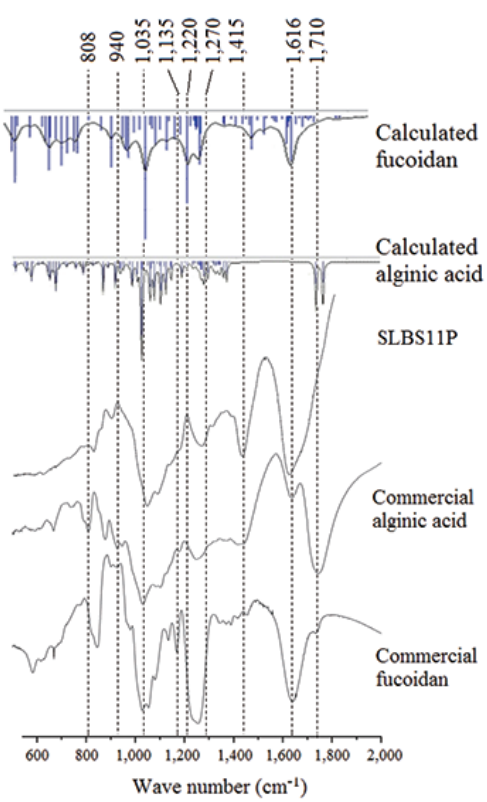

B

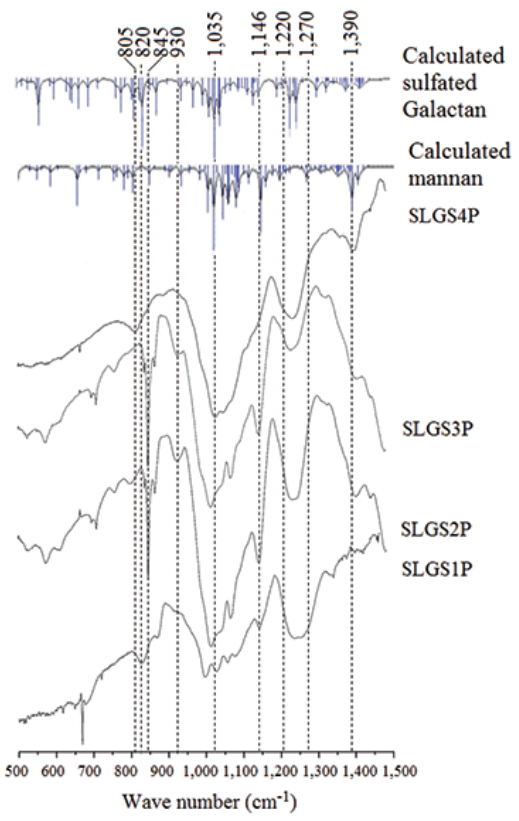

C

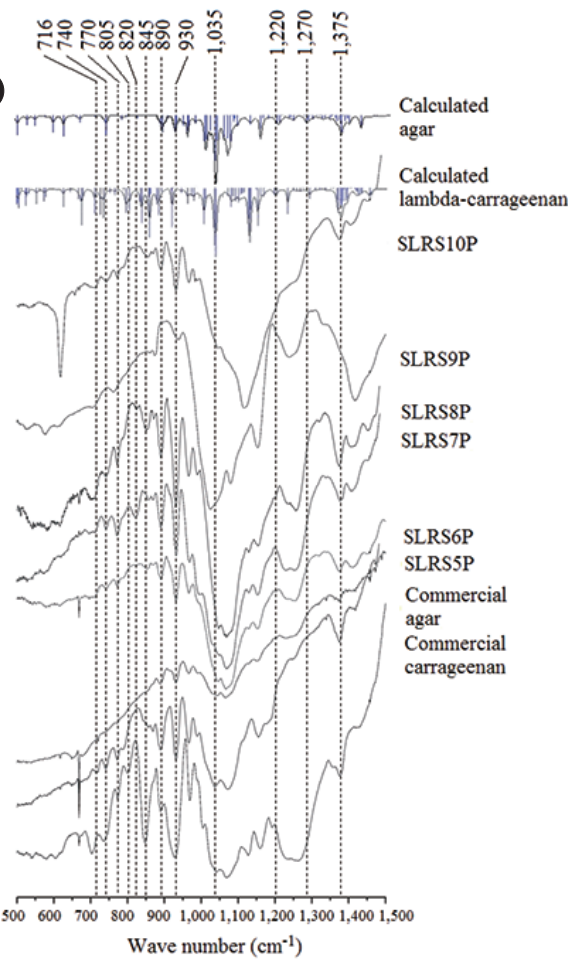

Fig. 3. Fourier transform infrared analysis of the crude polysaccharide fractions. (A) Brown algae crude polysaccharides. (B) Green algae crude polysaccharides. (C) Red algae crude polysaccharides. Experimental infrared (IR) spectra of the crude polysaccharide samples have been compared with IR spectra of standard polysaccharides and calculated IR spectra of constructed dimeric units of polysaccharides. Computational calculations were performed using density functional theory at RB3LYP/6-31G $(d, p)$ level. 
stretching) branching off from fucoidan or alginic acid residues. The IR band at $845 \mathrm{~cm}^{-1}$, shows the $\mathrm{C}-\mathrm{O}-\mathrm{S}$ bending vibration and further confirms the presence of a sulfate group. The peak at $1,616 \mathrm{~cm}^{-1}$ (Fig. 3A) is originated from the asymmetric stretching vibrations of the carboxylate $\mathrm{O}-\mathrm{C}-\mathrm{O}$ bond. The intense peak at $1,710 \mathrm{~cm}^{-1}$ in the commercial alginic acid indicates a stretching vibration of the carbonyl group in carboxylic acid groups $(\mathrm{C}=\mathrm{O})$, and the two peaks at 1,705 and $1,715 \mathrm{~cm}^{-1}$ in calculated alginic acid spectra confirms this feature (Jeon et al. 2002). The $1,710 \mathrm{~cm}^{-1}$ peak was not observed in SLBS11P, since alginic acid is clearly absent from SLBS11P. The absence of IR bands at $808 \mathrm{~cm}^{-1}\left(\mathrm{C}^{1}-\mathrm{H}\right.$ deformation vibration of guluronic acid residues), the bands at 808 and $822 \mathrm{~cm}^{-1}$ (guluronic acid residues), and the peak centered at 940 $\mathrm{cm}^{-1}$ (stretching vibration of $\mathrm{C}-\mathrm{O}$ in uronic acid residues) further confirm this scenario (Chandía et al. 2001, 2004, Leal et al. 2008).

Considering the polysaccharides found in green algae, seaweed galactans have IR peaks at 930, 845, 820, and 805 $\mathrm{cm}^{-1}$ (Fig. 3B) associated with 3,6-anhydrogalactose and the sulfation of C-4, C- 6 of galactose units and of C-2 of 3,6-anhydrogalactose (Matsuhiro 1996). The broadened IR peak between 1,120 and $1,270 \mathrm{~cm}^{-1}$ is indicative of the $\mathrm{S}=\mathrm{O}$ stretching vibration of sulfate groups, which was observed in all the green algal polysaccharide samples. The peak near $1,380 \mathrm{~cm}^{-1}$ is also indicative of sulfate substitution (Fenoradosoa et al. 2009). Peaks at 1,146 and $1,390 \mathrm{~cm}^{-1}$ are due to the presence of mannans (Dunn et al. 2007).

For red algal polysaccharides, the characteristic peak at $930 \mathrm{~cm}^{-1}$ (Fig. $3 \mathrm{C}$ ) represents the $\mathrm{C}-\mathrm{O}-\mathrm{C}$ vibration of

Table 4. A list of infrared (IR) vibrational modes characteristic to polysaccharides

\begin{tabular}{ll}
\hline IR absorption wave number $\left(\mathbf{c m}^{-1}\right)$ & \multicolumn{1}{c}{ Signal characteristics } \\
\hline $3,500-3,200$ & The broad peak signifies the stretching vibrations of the OH group \\
1,650 & Represent the carbonyl group of a carboxylic acid group \\
1,135 & Stretching vibrations of the glycosidic C-O bond \\
$1,315-1,220$ and $1,140-1,050$ & Symmetric and asymmetric stretching vibrations of the RO-SO ${ }^{3-}$ bond of the sulfate groups \\
1,370 & Sulfate groups \\
1,250 & The asymmetric stretching of S=O \\
930 & The vibration of the C-O-C bridge of 3,6-anhydro-L-galactose and 3,6-anhydro-D-galactose \\
& (common to both agar and carrageenan) \\
890 & Anomeric CH of $\beta$-galactopyranosyl residues \\
840 & Sulfation on C4 galactose \\
830 & Sulfation on C2 galactose units \\
805 & Sulfation on C2 of the 3,6-anhydro-L-galactose \\
740 and 716 & C-O-C bending vibrations in glycosidic linkages \\
$1,210-1,280$ & Broadband represents the sulfate group \\
822 & Mannuronic unit (characteristic band) \\
808 & Guluronic unit (characteristic band) \\
\hline
\end{tabular}

Table 5. Monosaccharide composition of the eleven crude algal polysaccharide fractions

\begin{tabular}{lcccccc}
\hline & \multicolumn{3}{c}{ Mono sugar (\%) } \\
\cline { 2 - 7 } Sample No. & Fucose & Rhamnose & Galactose & Glucose & Mannose & Xylose \\
\hline SLGS1P & 0.57 & 22.40 & 34.24 & 23.47 & 11.93 & 7.40 \\
SLGS2P & 0.79 & 3.10 & 11.86 & 52.27 & 11.91 & 20.07 \\
SLGS3P & 0.86 & 3.27 & 12.75 & 53.81 & 10.18 & 19.12 \\
SLGS4P & 1.31 & 5.52 & 27.61 & 32.71 & 17.49 & 15.36 \\
SLRS5P & 1.85 & 8.40 & 47.13 & 23.25 & 11.33 & 8.03 \\
SLRS6P & 1.76 & 8.05 & 37.56 & 34.74 & 11.83 & 6.05 \\
SLRS7P & 1.80 & 0.64 & 52.84 & 30.45 & 10.02 & 4.25 \\
SLRS8P & 1.01 & 10.33 & 35.63 & 31.58 & 14.49 & 6.96 \\
SLRS9P & 1.66 & 4.72 & 29.66 & 48.41 & 11.98 & 3.57 \\
SLRS10P & 1.93 & 5.65 & 59.59 & 16.71 & 14.33 & 1.78 \\
SLBS11P & 33.25 & 3.70 & 7.08 & 29.59 & 19.24 & 7.15 \\
\hline
\end{tabular}


3,6-anhydro-L-galactose and 3,6-anhydro-D-galactose residues found in both agar and carrageenan. The peak near $1,375 \mathrm{~cm}^{-1}$ indicates the presence of sulfate groups. Peaks at 740 and $716 \mathrm{~cm}^{-1}$ are associated with the $\mathrm{C}-\mathrm{O}-\mathrm{C}$ bending vibration separately in glycosidic linkages. The peak at $890 \mathrm{~cm}^{-1}$ represents the stretching vibration of the anomeric $\mathrm{C}$-H of unsulfated $\beta$-galactopyranosyl residues. Based on their degree interaction with sulfates, carrageenans are categorized into several types (Roberts and Quemener 1999). The peak between 1,210 and $1,270 \mathrm{~cm}^{-1}$ is associated with stretching vibration of the $\mathrm{S}=\mathrm{O}$ bond in sulfate groups, which is generally observable in all carrageenan types. This feature was observed in commercial lambda-carrageenan, SLRS6P, SLRS7P, SLRS8P, and SLRS9P but not SARS10P. According to Roberts and Quemener's characteristic spectral features can be observed in different carrageenan types (Roberts and Quemener 1999): peaks at $840-850 \mathrm{~cm}^{-1}$ (D-galactose-4-sulfate), at $820-830$ $\mathrm{cm}^{-1}$ (D-galactose-2-sulfate), and between 800 and $805 \mathrm{~cm}^{-1}$ (3,6-anhydro-D-galactose-2-sulfate). The weak band observed at $770 \mathrm{~cm}^{-1}$ shows the skeletal bending of galactose rings (Pereira et al. 2003).

\section{Monosaccharide composition of CP fractions}

The monosaccharide analysis revealed relatively higher glucose levels in green algae (Table 5), except for SLGS1P that was mainly composed of galactose. Red algae had higher levels of galactose and glucose. Except for SLRS9P, red algae had higher galactose levels than glucose levels. All green and red algal CPs indicated negligible amounts of fucose, whereas the highest reported level of fucose was from the CPs of the SLBS11P brown algae.

\section{DISCUSSION}

Marine algae have been widely investigated for their secondary metabolites that possess a wide range of biological activities. Among them algal polysaccharides receive special attention being structurally diversified with decorative functional groups such as sulfate groups. The aim of this study was to extract water soluble CPs from underexplored marine algae harvested from coastal areas of Sri Lanka and to evaluate their antioxidant activities and characterize the structural properties using FTIR analysis.

Being hydrophilic in nature, polysaccharides baring hydroxyl, carboxyl and / or sulfate groups could easily be dissolved in water. The use of hot water to extract algal polysaccharides seems to be a convenient way to enrich CPs. Hydrophilic compounds other than polysaccharides, however cannot be dissolved in water. Ethanol precipitation was therefore employed to precipitate polysaccharides from the mixture by reducing the dielectric constant of the solvent. The yields for the polysaccharides were all higher than 55\% (excluding the sulfate attachments) and this was indicative of the reliability of this methodology to obtain CPs. As described by Wijesinghe and Jeon (2012b), however, CPs can form strong intermolecular bonds with phenolic compounds and intra molecular bonds with proteins (glycoproteins). According to literature, the sulfate content and its positioning on the macromolecular backbone of polysaccharides can provide important information to compare their physicochemical characteristics (Wijesinghe and Jeon 2012a). CPs from the brown alga C. minima (SLBS11P) showed comparably high antioxidant activities. The higher levels of sulfate and polyphenols found in the SLBS11P and SLGS1P fractions might have contributed to the antioxidant radical scavenging activities of these $\mathrm{CP}$ fractions (Fig. 1).

With quantum chemistry calculation methods, vibrational spectra were obtained for the dimeric units of the major polysaccharides found in algae. The same method has been used by Cardenas-Jiron to compare the FTIR spectra of alginic acid with sample spectra (CardenasJiron et al. 2011). The negative values of "Sum of electronic and thermal free energies" for the constructed dimeric units of polysaccharides suggest stable molecular structures (Fig. 2). The corresponding sample spectra demonstrated the robustness of the DFT approach to predict FTIR spectra (Fig. 3). Alginic acid and fucoidan are the major polysaccharides found in brown algae (Percival 1979). Although alginic acid is the major polysaccharide in brown algae, it's insolubility in neutral water resulted in the absence of alginic acid from SLBS11P during the extraction procedure. Alginic acid in brown algae consist of D-mannuronic acid and L-guluronic acid. Fucoidan is a SP that mainly contains fucose with varying amounts of galactose, mannose, xylose and glucuronic acid. In addition, fucoidan found in brown algae is widely studied for its biofunctional properties (Wijesekara et al. 2011). Based on FTIR and monosaccharide analysis the polysaccharides obtained from C. minima whereas mainly found to contain fucoidan. Green algae contain highly branched complex molecules of galactans, mannans, and xylans composed of galactose, mannose and xylose units. Moreover, glucuronoxylorhamnan a SP has also been identified in some green algae, and is composed of glucose and rhamnose units (Percival 1979). According to FTIR and 
monosaccharide analyses SLGS1P, SLGS2P, SLGS3P, and SLGS4P contain galactans and mannans. The major polysaccharides in red algae are galactans that include agar, carrageenan, floridean starch and xylan. Galactose is the major monosaccharide found in red algae that builds up galactans (agar and carrageenan). Moreover, red algae contain floridean starch and xylan composed of glucose and xylose units respectively (Percival 1979). All investigated red algal CPs except SARS10P were characterized by the presence of agar and carrageenan whereas, SARS10P was characterized by abundance of agar.

The chemical mechanism(s) behind polysaccharide antioxidant activity has(have) not systematically been elucidated to date. However, as literature suggest, the higher degree of sulfation in these fucoidans might be attributed to the observed antioxidant activity (Ananthi et al. 2010). Polyphenols bound to polysaccharides might also contribute to the observed antioxidant activity. Further investigation is needed to separate and further purify these polysaccharides and to identify their sequence, monosaccharide composition, and other structural properties.

\section{ACKNOWLEDGEMENTS}

This research was a part of the project titled 'Development of overseas marine bio-resources and a system for their utilization,' funded by the Ministry of Oceans and Fisheries, Korea. We would also like to thank Department of Wildlife Conservation, Sri Lanka for granting the permission to collect the algae from aforementioned sampling sites.

\section{REFERENCES}

Alves, A., Caridade, S. G., Mano, J. F., Sousa, R. A. \& Reis, R. L. 2010. Extraction and physico-chemical characterization of a versatile biodegradable polysaccharide obtained from green algae. Carbohydr. Res. 345:2194-2200.

Ananthi, S., Raghavendran, H. R. B., Sunil, A. G., Gayathri, V., Ramakrishnan, G. \& Vasanthi, H. R. 2010. In vitro antioxidant and in vivo anti-inflammatory potential of crude polysaccharide from Turbinaria ornata (Marine Brown Alga). Food Chem. Toxicol. 48:187-192.

Cardenas-Jiron, G., Leal, D., Matsuhiro, B. \& Osorio-Roman, I. O. 2011. Vibrational spectroscopy and density functional theory calculations of poly-D-mannuronate and heteropolymeric fractions from sodium alginate. J. Ra- man Spectrosc. 42:870-878.

Chandía, N. P., Matsuhiro, B., Mejías, E. \& Moenne, A. 2004. Alginic acids in Lessonia vadosa: partial hydrolysis and elicitor properties of the polymannuronic acid fraction. J. Appl. Phycol. 16:127-133.

Chandía, N. P., Matsuhiro, B. \& Vásquez, A. E. 2001. Alginic acids in Lessonia trabeculata: characterization by formic acid hydrolysis and FT-IR spectroscopy. Carbohydr. Polym. 46:81-87.

Chandler, S. F. \& Dodds, J. H. 1983. The effect of phosphate, nitrogen and sucrose on the production of phenolics and solasodine in callus cultures of Solanum laciniatum. Plant Cell Rep. 2:205-208.

Christiaen, D. \& Bodard, M. 1983. Spectroscopie infrarouge de films d'agar de Gracilaria verrucosa (Huds.) Papenfuss. Bot. Mar. 26:425-427.

Coppejans, E., Leliaert, F., Dargent, O., Gunasekara, R. \& De Clerck, O. 2009. Sri Lankan seaweeds: methodologies and field guide to the dominant species. Abc Taxa 6:1265.

Dodgson, K. S. \& Price, R. G. 1962. A note on the determination of the ester sulphate content of sulphated polysaccharides. Biochem. J. 84:106-110.

DuBois, M., Gilles, K. A., Hamilton, J. K., Rebers, P. A. \& Smith, F. 1956. Colorimetric method for determination of sugars and related substances. Anal. Chem. 28:350-356.

Dunn, E. K., Shoue, D. A., Huang, X., Kline, R. E., MacKay, A. L., Carpita, N. C., Taylor, I. E. \& Mandoli, D. F. 2007. Spectroscopic and biochemical analysis of regions of the cell wall of the unicellular 'mannan weed', Acetabularia acetabulum. Plant Cell Physiol. 48:122-133.

Durairatnam, M. 1961. Contribution to the study of the marine algae of Ceylon. Bull. Fish. Res. Stn. Ceylon 10:1-181.

Engelmann, J., Volk, J., Leyhausen, G. \& Geurtsen, W. 2005. ROS formation and glutathione levels in human oral fibroblasts exposed to TEGDMA and camphorquinone. J. Biomed. Mater. Res. B Appl. Biomater. 75:272-276.

Fenoradosoa, T. A., Delattre, C., Laroche, C., Wadouachi, A., Dulong, V., Picton, L., Andriamadio, P. \& Michaud, P. 2009. Highly sulphated galactan from Halymenia durvillei (Halymeniales, Rhodophyta), a red seaweed of Madagascar marine coasts. Int. J. Biol. Macromol. 45:140-145.

Finkelstein, E., Rosen, G. M. \& Rauckman, E. J. 1980. Spin trapping of superoxide and hydroxyl radical: practical aspects. Arch. Biochem. Biophys. 200:1-16.

Fleita, D., El-Sayed, M. \& Rifaat, D. 2015. Evaluation of the antioxidant activity of enzymatically-hydrolyzed sulfated polysaccharides extracted from red algae: Pterocladia capillacea. LWT Food Sci. Technol. 63:1236-1244.

Heo, S. -J., Cha, S. -H., Lee, K. -W. \& Jeon, Y. -J. 2006. Anti- 
oxidant activities of red algae from Jeju Island. Algae 21:149-156.

Hiramoto, K., Johkoh, H., Sako, K. \& Kikugawa, K. 1993. DNA breaking activity of the carbon-centered radical generated from 2,2'-azobis(2-amidinopropane) hydrochloride (AAPH). Free Radic. Res. Commun. 19:323-332.

Horwitz, W. \& Latimer, G. W. Jr. 2005. Official methods of analysis of AOAC International. 18th ed. AOAC International, Gaithersburg, MD.

Jeon, C., Park, J. Y. \& Yoo, Y. J. 2002. Characteristics of metal removal using carboxylated alginic acid. Water Res. 36:1814-1824.

Ji, C. -F., Ji, Y. -B. \& Meng, D. -Y. 2013. Sulfated modification and anti-tumor activity of laminarin. Exp. Ther. Med. 6:1259-1264.

Kandasamy, S., Khan, W., Kulshreshtha, G., Evans, F., Critchley, A. T., Fitton, J. H., Stringer, D. N., Gardiner, V. -A. \& Prithiviraj, B. 2015. The fucose containing polymer (FCP) rich fraction of Ascophyllum nodosum (L.) Le Jol. protects Caenorhabditis elegans against Pseudomonas aeruginosa by triggering innate immune signaling pathways and suppression of pathogen virulence factors. Algae 30:147-161.

Kang, M. -C., Kim, S. -Y., Kim, E. -A., Lee, J. -H., Kim, Y. -S., Yu, S. -K., Chae, J. B., Choe, I. -H., Cho, J. H. \& Jeon, Y. -J. 2015. Antioxidant activity of polysaccharide purified from Acanthopanax koreanum Nakai stems in vitro and in vivo zebrafish model. Carbohydr. Polym. 127:38-46.

Kim, S. -Y., Kim, E. -A., Kang, M. -C., Lee, J. -H., Yang, H. -W., Lee, J. -S., Lim, T. I. \& Jeon, Y. -J. 2014. Polyphenol-rich fraction from Ecklonia cava (a brown alga) processing by-product reduces LPS-induced inflammation in vitro and in vivo in a zebrafish model. Algae 29:165-174.

Lakmal, H. H. C., Samarakoon, K. W., Lee, W., Lee, J. -H., Abeytunga, D. T. U., Lee, H. -S. \& Jeon, Y. -J. 2014. Anticancer and antioxidant effects of selected Sri Lankan marine algae. J. Natl. Sci. Found. Sri Lanka 42:315-323.

Leal, D., Matsuhiro, B., Rossi, M. \& Caruso, F. 2008. FT-IR spectra of alginic acid block fractions in three species of brown seaweeds. Carbohydr. Res. 343:308-316.

Lee, S. -H., Kang, S. -M., Sok, C. H., Hong, J. T., Oh, J. -Y. \& Jeon, Y. -J. 2015. Cellular activities and docking studies of eckol isolated from Ecklonia cava (Laminariales, Phaeophyceae) as potential tyrosinase inhibitor. Algae 30:163-170.

Lee, S. -H., Ko, C. -I., Jee, Y., Jeong, Y., Kim, M., Kim, J. -S. \& Jeon, Y. -J. 2013. Anti-inflammatory effect of fucoidan extracted from Ecklonia cava in zebrafish model. Carbohydr. Polym. 92:84-89.

Mahendran, M., Sirisena, D. M., Morisaki, M., Sano, F., Ikeka- wa, N. \& Sivapalan, A. 1980. Sterols of some Sri Lankan marine algae. J. Natl. Sci. Counc. Sri Lanka 8:69-74.

Marais, M. -F. \& Joseleau, J. -P. 2001. A fucoidan fraction from Ascophyllum nodosum. Carbohydr. Res. 336:155-159.

Mathlouthi, M. \& Koenig, J. L. 1987. Vibrational spectra of carbohydrates. Adv. Carbohydr. Chem. Biochem. 44:789.

Matsuhiro, B. 1996. Vibrational spectroscopy of seaweed galactans. Hydrobiologia 326:481-489.

Mollet, J. -C., Rahaoui, A. \& Lemoine, Y. 1998. Yield, chemical composition and gel strength of agarocolloids of Gracilaria gracilis, Gracilariopsis longissima and the newly reported Gracilaria cf. vermiculophylla from Roscoff (Brittany, France). J. Appl. Phycol. 10:59-66.

Nanjo, F., Goto, K., Seto, R., Suzuki, M., Sakai, M. \& Hara, Y. 1996. Scavenging effects of tea catechins and their derivatives on 1,1-diphenyl-2-picrylhydrazyl radical. Free Radic. Biol. Med. 21:895-902.

Nishiguchi, T., Jiang, Z., Ueno, M., Takeshita, S., Cho, K., Roh, S. W., Kang, K. -H., Yamaguchi, K., Kim, D. \& Oda, T. 2014. Reevaluation of bactericidal, cytotoxic, and macrophage-stimulating activities of commercially available Fucus vesiculosus fucoidan. Algae 29:237-247.

Percival, E. 1979. The polysaccharides of green, red and brown seaweeds: their basic structure, biosynthesis and function. Br. Phycol. J. 14:103-117.

Pereira, L., Gheda, S. F. \& Ribeiro-Claro, P. J. A. 2013. Analysis by vibrational spectroscopy of seaweed polysaccharides with potential use in food, pharmaceutical, and cosmetic industries. Int. J. Carbohydr. Chem. 2013:537202.

Pereira, L., Sousa, A., Coelho, H., Amado, A. M. \& RibeiroClaro, P. J. A. 2003. Use of FTIR, FT-Raman and ${ }^{13} \mathrm{C}-\mathrm{NMR}$ spectroscopy for identification of some seaweed phycocolloids. Biomol. Eng. 20:223-228.

Praiboon, J., Chirapart, A., Akakabe, Y., Bhumibhamon, O. \& Kajiwarac, T. 2006. Physical and chemical characterization of agar polysaccharides extracted from the Thai and Japanese species of Gracilaria. Sci. Asia 32(Suppl. 1):1117.

Premakumara, G. A. S., Ratnasooriya, W. D. \& Tillekeratne, L. M. V. 1996. Isolation of a non-steroidal contragestative agent from Sri Lankan marine red alge, Gelidiella acerosa. Contraception 54:379-383.

Roberts, M. A. \& Quemener, B. 1999. Measurement of carrageenans in food: challenges, progress, and trends in analysis. Trends Food Sci. Technol. 10:169-181.

Tul'chinsky, V. M., Zurabyan, S. E., Asankozhoev, K. A., Kogan, G. A. \& Khorlin, A. Y. 1976. Study of the infrared spectra of oligosaccharides in the region 1,000-40 $\mathrm{cm}^{-1}$. Carbohydr. Res. 51:1-8. 
Vijayabaskar, P., Vaseela, N. \& Thirumaran, G. 2012. Potential antibacterial and antioxidant properties of a sulfated polysaccharide from the brown marine algae Sargassum swartzii. Chin. J. Nat. Med. 10:421-428.

Wijesekara, I., Pangestuti, R. \& Kim, S. -K. 2011. Biological activities and potential health benefits of sulfated polysaccharides derived from marine algae. Carbohydr. Polym. 84:14-21.

Wijesinghe, W. A., Senevirathne, M., Oh, M. -C. \& Jeon, Y. -J. 2011. Protective effect of methanol extract from citrus press cakes prepared by far-infrared radiation drying on $\mathrm{H}_{2} \mathrm{O}_{2}$-mediated oxidative damage in Vero cells. Nutr. Res. Pract. 5:389-395.

Wijesinghe, W. A. J. P. \& Jeon, Y. -J. 2012a. Biological activi- ties and potential industrial applications of fucose rich sulfated polysaccharides and fucoidans isolated from brown seaweeds: a review. Carbohydr. Polym. 88:13-20.

Wijesinghe, W. A. J. P. \& Jeon, Y. -J. 2012b. Enzyme-assistant extraction (EAE) of bioactive components: a useful approach for recovery of industrially important metabolites from seaweeds: a review. Fitoterapia 83:6-12.

Xia, S., Gao, B., Li, A., Xiong, J., Ao, Z. \& Zhang, C. 2014. Preliminary characterization, antioxidant properties and production of chrysolaminarin from marine diatom Odontella aurita. Mar. Drugs 12:4883-4897.

Yu, B. P. 1994. Cellular defenses against damage from reactive oxygen species. Physiol. Rev. 74:139-162. 